\title{
Estimating the Optimal Hedge Ratio in the Presence of Potential Unknown Structural Breaks
}

\author{
Abdulnasser Hatemi-J \\ UAE University \\ E-mail: $\underline{\text { AHatemi@uaeu.ac.ae }}$ \\ Eduardo Roca \\ Department of Accounting, Finance and Economics, \\ Griffith University \\ Nathan, Queensland, Australia 4111 \\ Tel: +61-7-38757583, Fax: +61-7-3875 7760 \\ Email: E.Roca@griffith.edu.au \\ (Corresponding Author)
}

\begin{abstract}
We propose a new approach in the estimation of the optimal hedge ratio that allows the hedge ratio to vary over time but without the necessity of frequently rebalancing the portfolio. We apply this in the context of the US and UK equity markets using weekly spot share prices and future share prices during the period January 5, 1999 to September 29, 2009. Our method is to test for cointegration in the presence of two potentially unknown structural breaks by determining the timing of each via the underlying data. The empirical findings reveal that the spot and future prices are strongly cointegrated in each market. The estimated parameters disclose that the optimal hedge ratio is not constant in case of the US and the UK. We find one negative and one positive shift in the optimal hedge ratio in the US. However, we find only one significant and positive shift in the optimal hedge ratio in the UK. The implication of these findings from the perspective of both investors as well as policy makers is elaborated on in the main text.
\end{abstract}

Running title: Calculating the Optimal Hedge Ratio in the US and the UK JEL Classification: G32, C30

Keywords: Optimal Hedge Ratio, Multiple Breaks, US, UK 


\subsection{Introduction}

The recent occurrence of the global financial crisis and the continuing turmoil in financial markets has further reinforced the utmost importance of the hedging of risk. Within the hedging process, the determination of the optimal quantity of the hedging instrument - the so-called hedge ratio, of course, plays a very critical role. The estimation of the optimal hedge ratio has therefore attracted considerable attention in the literature. Several approaches have been proposed and tested in different markets - both financial and non-financial. However, inspite of this, there is still no universal agreement as regards the approach to use in the estimation of the optimal hedge ratio.

In this paper, we propose to estimate the optimal hedge ratio based on a methodology which has not been explored yet in the literature on hedge ratio. One of the existing studies on hedge ratio - that of Hatemi-J and Roca (2006), demonstrated that the optimal hedge ratio is not constant. The authors defined a time-varying parameter model and calculated it by using the Kalman filter. However, allowing the optimal hedge ratio to change continuously during the time period means rebalancing the portfolio in each period, which might be too costly to the investors to implement. Therefore, finding the most significant shifts in the optimal hedge ratio might be more practical in terms of rebalancing the portfolio. With this as a motivation, in this paper, we propose to calculate the optimal hedge ratio based on a cointegration test in the presence of two potentially unknown structural breaks, as developed by Hatemi-J (2008). We apply this new methodology in the context of the US and UK equity markets based on weekly spot and future prices during the period January 5, 1999 to September 29, 2009

The rest of this paper is organised as follows. Section 2 presents a brief discussion of the optimal hedge ratio while Section 3 provides a literature review. Section 4 discusses the methodology while Section 5 presents the empirical results. Section 6 gives the conclusion of the study. 


\subsection{Optimal Hedge Ratio}

The optimal hedge ratio is defined as the quantities of the spot instrument and the hedging instrument that ensure that the total value of the hedged portfolio does not change. It can be formally expressed in terms of the following, as per Hatemi-J and Roca (2006):

$$
V_{h}=Q_{s} S-Q_{f} F
$$

Since the only source of uncertainty is the price we can also express equation (1) in terms of changes as the following:

$$
\Delta V_{h}=Q_{s} \Delta S-Q_{f} \Delta F
$$

where $V_{h}$ is the value of the hedged portfolio, $Q_{s}$ and $Q_{f}$ are the quantity of spot and futures instrument respectively, $S$ and $F$ are the price of spot and futures instrument respectively, $\Delta S=$ $S_{2^{-}} S_{1}$ and $\Delta F=F_{2^{-}} F_{1}$.

If $\Delta V_{h}=0$, which is the optimal goal of any hedging strategy, then $\frac{Q_{f}}{Q_{s}}=\frac{\Delta S}{\Delta F}$.

Let

$$
h=\frac{Q_{f}}{Q_{s}}
$$

then

$$
h=\frac{\Delta S}{\Delta F}
$$

where $h$ gives the hedge ratio. Therefore, the hedge ratio can be demonstrated as the slope coefficient in a regression of the price of the spot instrument on the price of the future (hedging) instrument. By substituting equation (3) into equation (2) we obtain the following: 


$$
\Delta V_{h}=Q_{s}[\Delta S-h \Delta F]
$$

The hedge ratio, however, depends on the objective function of the hedger. In this paper, we use variance minimisation as the objective function as this is the most popular and widely used hedging objective. Based on this approach, therefore, the optimal hedge ratio is the one that minimises the variance of the hedger's position. This is derived by minimising the variance of equation (5), which is:

$$
\operatorname{Var}\left[\Delta V_{h}\right]=Q_{s}^{2}\left[\sigma_{S}^{2}+h^{2} \sigma_{F}^{2}-2 h \rho \sigma_{S} \sigma_{F}\right]
$$

Where $\sigma_{S}^{2}$ is the variance of $\Delta S,\left(\sigma_{S}\right.$ is the standard deviation of $\left.\Delta S\right), \sigma_{F}^{2}$ is the variance of $\Delta F$, ( $\sigma_{F}$ is the standard deviation of $\Delta F$ ), and $\rho$ is the correlation coefficient between $\Delta S$ and $\Delta F$.

Thus, the minimum variance hedge ratio can be obtained by minimizing equation (6) with regard to $h$. By using the first order condition for optimization we have

$$
\frac{\partial\left[\operatorname{Var}\left[\Delta V_{h}\right]\right]}{\partial h}=Q_{s}^{2}\left[2 h \sigma_{F}^{2}-2 \rho \sigma_{S} \sigma_{F}\right]=0,
$$

That gives the following optimal hedge ratio:

$$
h^{*}=\rho \frac{\sigma_{S}}{\sigma_{F}^{2}} .
$$

Note that the second derivative of equation (6) with respect to $h$ is positive which fulfills the second order condition for minimization.

The minimum variance optimal hedge ratio is therefore the estimated parameter of the standard regression. However, in order to not lose long-run information we will make use of the variables 
in the level form. We will also allow for two unknown potential shifts in the optimal hedge ratio. This issue is described in details in the methodology section.

\subsection{Literature Review}

There are now a voluminous number of studies which have been conducted on the calculation of the optimal hedge ratio. Various approaches have been proposed and used in the estimation of the optimal hedge ratio in the context of different markets - financial as well as non-financial markets such as agricultural, metal, energy, among others.

The methodology applied to hedge ratio estimations generally range from the ordinary least squares (OLS), to the error correction model (ECM), generalised autoregressive conditional heteroskadisticity. The shortcomings of the OLS, however, is already well known in that it does not take into consideration time varying distributions, serial correlation, heteroscedasticity and cointegration (Poterba and Summers, 1986; Bollerslev, 1986; Baillie and De Gennaro, 1990). This can therefore lead to model specification and as pointed by Hatemi-J and Roca (2006), this can result in downward bias in the hedge ratio estimates and consequently, under-hedging.

To overcome the weaknesses of the OLS method, a number of researchers estimated the optimal hedge ratio based on the ECM approach. For example, Ghosh (1993) applied the ECM to estimate the optimal hedge ratio involving the S\&P futures, S\&P index, Dow Jones industry average and the NYSE composite index. This study was subsequently extended to the international setting by Ghosh and Clayton (1996), where they included the CAC 40 (France), FTSE 100 (UK), DAX (Germany) and the Nikkei (Japan) index. Both studies found that the ECM hedge ratios performed better than the OLS hedge ratios. This result was also obtained by Kenourgios et al (2008 in their investigation of the hedging effectiveness of the S\&P 500 futures contract for the period July 1992 - June 2002. Other studies using the ECM which found similar results are those of Chou et al., 1996; Lien, 1996; Sim and Zurbruegg, 2001; Moosa, 2003 among others. 
The ECM method, however, does not take into account the so-called autoregressive conditional heteroskedasticity $(\mathrm{ARCH})$ effects which is already well-documented in the literature. In order to address this issue, a number of studies have estimated the hedge ratio using models that explicitly incorporate ARCH effects. Kroner and Sultan (1993), for instance, utilised a bivariate VECM with a GARCH error structure in calculating the hedge ratio in relation to the hedging of different currencies - British pound, the Canadian dollar, the German mark, the Japanese yen, and the Swiss franc with futures contracts in the International Monetary Market. Baillie and Myers (1991) also employed a bivariate GARCH model to estimate hedge ratios in relation to six different commodities, namely beef, coffee, corn, cotton, gold and soybean. Park and Switzer (1995) tested the S\&P 500 and Toronto 35 index futures. They both found that the performance is far superior to a constant hedge ratio. More recently, Yang and Awokuse (2003) examined corn, soybean, wheat, cotton and sugar (as storable commodities) and lean hogs, live cattle and feeder cattle (as non storable commodities), and found that BGARCH is strong for all storable commodities but weak for non storable commodities. Yang and Allen (2004) and Kenourgios, Samitas and Drosos (2008) employed the VECM-GARCH model in estimating hedge ratios with regards to the hedging of the all ordinary stock index in Australia and the S\&P 500 stock index in the U.S, respectively. These studies found that the hedge ratios estimates based on models with ARCH effects have better hedging performance than those obtained based on the OLS method. A hedge ratio study by Floros and Vougas (2004) based on the Greek stock and futures market from 1999 to 2001 even found the bivariate GARCH model to have outperformed the ECM and VECM models.

As mentioned earlier, these different optimal hedge ratio estimation approaches have been applied in various markets - both financial as well non-financial ones such as, for instance, agricultural and energy markets, among others. For example, Ghosh and Clayton (1996) and Kenourgios, et al (2008) estimated hedge ratios for the stock index; Copeland and Zhu (2006) for the foreign exchange market, Yang and Awokuse (2003) for agricultural and livestock and Cecchetti et al. (1988) for fixed-income securities. Most of the ratios that they obtained lie within the range of 0.5 to 1 . In Baillie and Myers (1991), the hedge ratio for beef was found to have zero variance reduction, which in other words is not recommended for hedging application. This was later confirmed in Yang and Awokuse (2003), where the hedge ratio for live cattle did 
not produce much variance reduction compared to no hedge at all.

It appears therefore that hedge ratios estimated based on time varying models, such as the ones that incorporate $\mathrm{ARCH}$ effects, as discussed earlier, seem to produce better performance. A relatively recent study - that of Hatemi-J and Roca (2006), provides further confirmation of this. Applying the Kalman Filter method, they demonstrated that hedge ratios estimated based on this method performed better than those based on constant parameter models. However, the practical implementation of this time varying hedge ratios might pose a problem as this may entail a significant cost in terms of frequent rebalancing of the portfolio. In this paper, we therefore address this issue. We propose to calculate the hedge ratio based on a cointegration approach in the presence of two potentially unknown structural breaks which are identified through the underlying data. Finding the significant shifts in the hedge ratio would be a more practical approach in terms of rebalancing the portfolio. We contribute to the literature on hedge ratio as this particular approach has not been explored yet in the said literature.

\subsection{Methodology and Data Set}

It is widely accepted in the econometric literature that tests for cointegration have low power properties if the effect of potential structural breaks are not taken into account. We take this issue into account by using the following regression model to calculate the optimal hedge ratio:

$$
S_{t}=\alpha_{0}+\alpha_{1} D_{1 t}+\alpha_{2} D_{2 t}+\beta_{0} F_{t}+\beta_{1} D_{1 t} F_{t}+\beta_{2} D_{2 t} F_{t}+u_{t}
$$

where $S_{t}$ is the spot price index, $F_{t}$ is the future price index. The parameter $\beta_{0}$ is representing the optimal hedge ratio, while $\beta_{1}$ signifies the first change and $\beta_{2}$ the second change in the optimal hedge ratio. The indicator variables to taken into account the effect of potential breaks are denoted by $D_{1 t}$ and $D_{2 t}$ which are defined in the following form:

$$
D_{1 t}=\left\{\begin{array}{lll}
0 & \text { if } & t \leq\left[n \tau_{1}\right] \\
1 & \text { if } & t>\left[n \tau_{1}\right]
\end{array} \text { and } D_{2 t}=\left\{\begin{array}{lll}
0 & \text { if } & t \leq\left[n \tau_{2}\right] \\
1 & \text { if } & t>\left[n \tau_{2}\right]
\end{array}\right.\right.
$$


The timing of structural change is indicated by the unknown parameters $\tau_{1} \in(0,1)$ and $\tau_{2} \in(0,1)$. The integer part is denoted by the bracket since $n$ is the number of observations. We make use of three cointegration tests. One of these is the ADF test which is a $t$-test for the slope of $\hat{u}_{t-1}$ in a regression of $\Delta \hat{u}_{t}$ on $\hat{u}_{t-1}, \Delta \hat{u}_{t-1}, \cdots, \Delta \hat{u}_{t-k}$, where $\hat{u}_{t}$ is the residual term from the regression specified in Equation (9). We determine the optimal lag length, $k$, by minimising an information criterion. The other two tests are based on the $Z_{\alpha}$ and $Z_{t}$ test statistics, originally developed by Phillips (1997), which are derived through the following bias-corrected first-order serial correlation coefficient estimate

$$
\hat{\rho}^{*}=\frac{\sum_{t=1}^{n-1}\left(\hat{u}_{t} \hat{u}_{t+1}-\sum_{j=1}^{B} w(j / B) \hat{\gamma}(j)\right)}{\sum_{t=1}^{n-1} \hat{u}_{t}^{2}},
$$

where $w(\cdot)$ is a function that provides kernel weights fulfilling the standard conditions for spectral density estimators, $B$ is the bandwidth number satisfying the conditions $B \rightarrow \infty$ and $B / n^{5}=$ $\mathrm{O}(1)$. The autocovariance function is given as

$$
\hat{\gamma}(j)=\frac{1}{n} \sum_{t=j+1}^{T}\left(\hat{u}_{t-j}-\hat{\rho} \hat{u}_{t-j-1}\right)\left(\hat{u}_{t}-\hat{\rho} \hat{u}_{t-1}\right),
$$

where $\hat{\rho}$ is the OLS estimate of the effect (without intercept) of $\hat{a}_{t-1}$ on $\hat{u}_{t}$. We define the $Z_{\alpha}$ and $Z_{t}$ test statistics as

$$
Z_{\alpha}=n\left(\hat{\rho}^{*}-1\right)
$$

and

$$
Z_{t}=\frac{\left(\hat{\rho}^{*}-1\right)}{\left(\hat{\gamma}(0)+2 \sum_{j=1}^{B} w(j / B) \hat{\gamma}(j)\right) / \sum_{1}^{n-1} \hat{u}_{t}^{2}}
$$

where $\hat{\gamma}(0)+2 \sum_{j=1}^{B} w(j / B) \hat{\gamma}(j)$ is the long-run variance estimate of the residuals of a regression of $\hat{u}_{t}$ on $\hat{u}_{t-1} \cdot 1$

\footnotetext{
${ }^{1}$ The estimation for the long-run variance utilizes an automatic bandwidth estimator and a prewhitened quadratic spectral kernel with a first-order autoregression for the prewhitening. For details, Gregory and Hansen (1996) refer us to Andrews (1991) and Andrews and Monahan (1992).
} 
The relevant test statistics are the lowest values of these three tests across all possible values for $\tau_{1}$ and $\tau_{2}$, with $\tau_{1} \in T_{1}=(0.15,0.70)$ and $\tau_{2} \in T_{2}=\left(0.15+\tau_{1}, 0.85\right)$. We choose the smallest value for each test statistic since this represents the empirical evidence against the null hypothesis. ${ }^{2}$ These test statistics are defined as

$$
\begin{aligned}
& A D F^{*}=\inf _{\left(\tau_{1}, \tau_{2}\right) \in T} A D F\left(\tau_{1}, \tau_{2}\right), \\
& Z_{t}^{*}=\inf _{\left(\tau_{1}, \tau_{2}\right) \in T} Z_{t}\left(\tau_{1}, \tau_{2}\right), \\
& Z_{\alpha}^{*}=\inf _{\left(\tau_{1}, \tau_{2}\right) \in T} Z_{\alpha}\left(\tau_{1}, \tau_{2}\right),
\end{aligned}
$$

where $T=(0.15 n, 0.85 n)$. Following Gregory and Hansen (1996), we have truncated the data by $15 \%$ on both ends of the distribution and allow the gap between the two regime shifts to be at least 15\%. Hatemi-J (2008) demonstrates that these three test statistics possess non-standard distributions in the presence of two structural breaks. Through simulation methods, the author has produced new critical values, which we use in this study. We conduct the estimations in this study by using a Gauss program procedure produced by Hatemi-J (2009), which is available online.

The dataset used in this paper consists of weekly observations of spot and future prices for the UK and the US during the period January 5, 1999 to September 29, 2009 which are collected from DataStream.

\subsection{Empirical Findings}

We started our analysis by testing for unit roots of each variable by using the Ng-Perron unit root tests that allows for multiple breaks in the deterministic components. The results, not reported revealed that each variable contains one unit root. Thus, in order to avoid spurious inference we conducted tests for cointegration with two unknown breaks.

\footnotetext{
${ }^{2}$ See also Gregory and Hansen (1996).
} 
We found two potential unknown structural breaks corresponding to the second week of September 2001 (September 11 terrorist attack) and third week of March 2003 (Iraq War). The results of the tests for cointegration with potential two unknown breaks are presented in Table 2. These tests results reveal that there is a long run steady state relationship between the spot process and futures prices in the US as well as the in the UK financial market in the presence of structural breaks.

Table 2. The Results of Tests for Cointegration with Two Unknown Shifts between Spot and Future Prices.

\begin{tabular}{|c|c|c|}
\hline \multirow{3}{*}{ Currency } & Test Statistic & $\begin{array}{c}\text { Estimated Test } \\
\text { Value }\end{array}$ \\
\hline \multirow{4}{*}{$U S$} & $A D F^{*}$ & -7.864 \\
\cline { 2 - 3 } & $Z^{*}{ }_{t}$ & -9.775 \\
\cline { 2 - 3 } & $Z^{*}{ }_{\alpha}$ & -155.160 \\
\hline \multirow{3}{*}{$U K$} & $A D F^{*}$ & -6.270 \\
\cline { 2 - 3 } & $Z^{*}{ }_{t}$ & -6.253 \\
\cline { 2 - 3 } & $Z^{*}{ }_{\alpha}$ & -73.076 \\
\hline
\end{tabular}

Notes: The critical values are $-6.503(1 \%),-6.015(5 \%)$, and $-5.653(10 \%)$ for the $A D F^{*}$ test as well as the $Z_{t}^{*}$ test. The critical values for the $Z_{\alpha}{ }^{*}$ test are $-90.794(1 \%),-76.003(5 \%)$, and $-52.232(10 \%)$. These critical values are collected from Hatemi-J (2008).

The estimated cointegrating parameters are presented in Table 3. For the US market, these estimated values reveal that the optimal hedge ratio is 0.957 before the first structural break period; it then increases by 0.051 after the first break period and later decreases by -0.032 after the second break period. All three of these parameters are statistically significant at any conventional significance level. In the case of the UK market, the estimated optimal hedge ratio is 1.128 and statistically significant before the first break in the UK. This decreases by 0.134 after the first break; however, this decrease is not statistically significant. After the second period, there is a significant increase in the estimated optimal hedge ratio by 0.421 . Thus, these results show that the optimal hedge ratio is not constant in either the US or the UK market. In the case of the US, there are two significant shifts statistically speaking; however, there is only one significant shift in the case of the UK. 
Table 3. The Estimated Values of the Cointegrating Parameters with Shifts.

\begin{tabular}{|c|c|c|c|c|c|c|}
\hline Currency & $\alpha_{0}$ & $\alpha_{1}$ & $\alpha_{2}$ & $\beta_{0}$ & $\beta_{1}$ & $\beta_{2}$ \\
\hline \multirow{2}{*}{ US } & 0.278 & -0.395 & 0.231 & 0.957 & 0.051 & -0.032 \\
& $(4.238)$ & $(-5.880)$ & $(11.944)$ & $(105.547)$ & $(5.487)$ & $(-11.634)$ \\
\hline \multirow{2}{*}{ UK } & -2.798 & 1.237 & -3.479 & 1.128 & -0.134 & 0.421 \\
& $(-7.818)$ & $(1.314)$ & $(-3.925)$ & $(27.388)$ & $(-1.187)$ & $(3.946)$ \\
\hline
\end{tabular}

Notes: The t-values are presented in the parentheses.

\subsection{Conclusion}

In this paper we estimate the optimal hedge ratio in the US and the UK equity markets during the period January 5, 1999 to September 29, 2009. Weekly data are used. We apply cointegration tests in the presence of two potentially unknown structural breaks, as developed by Hatemi-J (2008). The results reveal that there is a steady state relationship between spot and futures prices. The optimal hedge ratio was, however, not constant for both the US and the UK during the sample period. Nevertheless, the change in the hedge ratio after each structural break was in opposite directions for the two markets. These hedge ratios, after taking into account their changes after each period, on the average, are still in line with those obtained in other markets. As these two hedge ratios only vary with the important structural changes, these allow the hedge ratios to be time varying but at the same time, it avoids frequent rebalancing and therefore avoid the higher costs associated with constantly time varying hedge ratios. 


\section{References}

Andrews, D.W.K. (1991) Heteroscedasticity and Autocorrelation Consistent Covariance Matrix Estimation, Econometrica, 59, 817-858.

Andrews, D.W.K. and Monahan, J.C. (1992) An Improved Heteroscedasticity and Autocorrelation Consistent Covariance Matrix Estimator, Econometrica, 60, 953-966.

Baillie, R. T. and Myers, R. J. (1991). Bivariate GARCH estimation of the optimal commodity futures hedge. Journal of Applied Econometrics, 6(2), 109-124.

Bollerslev, T. (1986). Generalized autoregressive conditional heteroskedasticity. Journal of Econometrics, 31(3), 307-327.

Cecchetti, S. G., Cumby, R. E., and Figlewski, S. (1988). Estimation of the optimal futures hedge. Review of Economics and Statistics, 70(4), 623-630.

Chou, W. L., Denis, K. K. F., and Lee, C. F. (1996). Hedging with the Nikkei Index Futures: the conventional model versus the error correction model. Quarterly Review of Economics and Finance, 36(4), 495-511.

Copeland, L. and Zhu, Y. (2006). Hedging effectiveness in the index futures market. Cardiff Business School.

Fan, J. (2010). Hedging with Futures Contract: Estimation and Performance Evaluation of the Optimal Hedge Ratio in the European Union Emissions Trading Scheme. an Honours dissertation submitted to Griffith University.

Floros, C. and Vougas, D. (2004) Hedge ratios in Greek stock index futures market, Applied Financial Economics, 14, 1125-36.

Gregory, A.W. and Hansen, B. E. (1996) "Residual-Based Tests for Cointegration in Models with Regime Shifts", Journal of Econometrics 70, 99-126.

Ghosh, A. (1993). Hedging with stock index futures: Estimation and forecasting with error correction model. Journal of Futures Markets, 13(7), 743-752.

Ghosh, A., \& Clayton, R. (1996). Hedging with international stock index futures: an intertemporal error correction model. Journal of Financial Research, 19(4), 477-492.

Hatemi-J A. (2008) Tests for Cointegration with Two Unknown Regime Shifts with an Application to Financial Market Integration, Empirical Economics, 35(3), 497-505. 
Hatemi-J A. (2009) CItest2b: GAUSS module to implement tests for cointegration with two unknown structural breaks," Statistical Software Components, nr. G00006, Boston College Department of Economics.

Hatemi-J, A., \& Roca, E. (2006). Calculating the optimal hedge ratio: constant, time varying and the Kalman Filter approach. Applied Economics Letters, 13(5), 293-299.

Kenourgios, D., Samitas, A., \& Drosos, P. (2008). Hedge ratio estimation and hedging effectiveness: the case of the S\&P 500 stock index futures contract. International Journal of Risk Assessment and Management, 9(1/2), 121-138.

Kroner, K. F., \& Sultan, J. (1993). Time-varying distributions and dynamic hedging with foreign currency futures. Journal of Financial and Quantitative Analysis, 28(4), 535-551.

Lien, D. (1996). The effect of the cointegration relationship on futures hedging: A note. Journal of Futures Markets, 16(7), 773-780.

Moosa, I. A. (2003). The sensitivity of the optimal hedge ratio to model specification. Finance Letters, 1(1), 15-20.

Ng, S., and P. Perron (2001). "Lag Length Selection and the Construction of Unit Root Tests with Good Size and Power," Econometrica, 69, 1519-1554.

Park, T. H. and Switzer, L. N. (1995). Time-varying distributions and the optimal hedge ratios for stock index futures. Applied Financial Economics, 5(3), 131-137.

Phillips, P.C.B. (1987) “Time Series Regression with a Unit Root”, Econometrica, 55, 277-301.

Poterba, J. M. and Summers, L. H. (1988). Mean reversion in stock prices: Evidence and Implications. Journal of Financial Economics, 22(1), 27-59.

Sephton, P. S. (1993). Hedging wheat and canola at the Winnipeg Commodity Exchange. Applied Financial Economics, 3(1), 67-72.

Sim, A.-B. and Zurbruegg, R. (2001). Optimal hedge ratios and alternative hedging strategies in the presence of cointegrated time-varying risks. The European Journal of Finance, $7(3), 269-283$.

Yang, J. W. and Allen, D. E. (2004). Multivariate GARCH hedge ratios and hedging effectiveness in Australian futures markets. Accounting and Finance, 45(2), 301-321.

Yang, J. and Awokuse, T. O. (2003). Asset storability and hedging effectiveness in commodity futures markets. Applied Economics Letters, 10(8), 487-491. 